PROGRESS REPOR'T

DOE/ER/13633--11

DE92 011808

\title{
Excited State Processes in Transition Metal Complexes. Redox Splitting in Soluble Polymers
}

Thomas J. Meyer

University of North Carolina

Chapel Hill, NC 27599-3290

\section{DISCLAIMER}

This report was prepared as an account of work sponsored by an agency of the United States Government. Neither the United States Government nor any agency thereof, nor any of their employees, makes any warranty, express or implied, or assumes any legal liability or responsibility for the accuracy, completeness, or usefulness of any information, apparatus, priduct, or process disclosed, or represents that its use would not infringe privately owned rights. Reference herein to any specific commercial product, process, or service by trade name, tradeinark, manufacturer, or otherwise does not necessarily constitute or imply its endorsement, recommendation, or favoring by the United States Government or any agency thereof. The views and opinions of authors expressed herein do not necessarily state or reflect those of the United States Government or any agency thereof.

November 15, 1991 - November 14, 1992

March 1992

Prepared for the U. S. Department of Energy under Contract Number DE-FG05-86ER 13633.

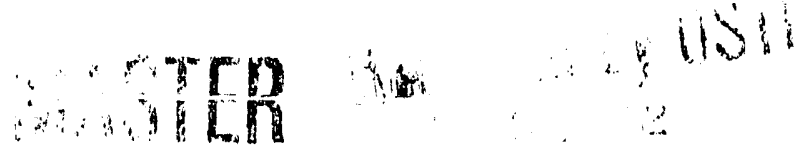




\section{IN'TRODUCTION}

In our DOE funded research in the last grant period, there were two major themes. The first was the continued development of MLCT excited states as sensitizers. In one sequence of experiments the synthetic aspects of this area were developed in further detail both by extending the chemistry of the polypyridyl-accepting ligands associated with the excited state and by developing a new procedure for the preparation of unsymmetrical tris-chelate complexes. The second important aspect of this work was the continued investigation of the molecular and electronic structure characteristics of this class of excited states and how those factors determine such properties as photostability and excited state decay. This effort was extended to complexes of $\operatorname{Re}(I)$ and an examination of their excited state characteristics, the role of the hydride ligand in determining the properties of MLCT excited states, the calculation of relative nonradiative decay rate constants for a series of complexes of $R u(I I)$, the participation of higher lying MLCT excited states in MLCT decay in complexes of $\mathrm{Ru}$ (II) and $\mathrm{Os}$ (II), and the application of the transient infrared (TRIR) technique to the elucidation of a photochemical intermediate following laser flash excitation.

The second area of study involved MLCT excited states in soluble polymers to investigate photoinduced electron and energy transfer in multi-component assemblies. This work was based on chemically derivatized polystyrene polymers which contain combinations of MLCT chromophores and electron or energy transfer quenchers. In these experiments it was possible to demonstrate: 1) the effect of electron and energy transfer shuttling following laser flash excitation of solutions containing chromophores and electron and energy transfer acceptors on separate polymeric strands, 2) the possibility of producing and storing multiple oxidative equivalents on single polymeric strands, 3) the measurement of rate constants for intrastrand electron and energy transfer following laser flash excitation, and 4) 10 demonstrate the existence of long-range intrastrand energy transfer by the exploitation of an energy transfer cascade.

In addition to the advances made in these areas, our DOE supported effort was featured in three review articles. In one, a general approach to artificial photosynthesis was developed based on MLCT excited states. In another, the emphasis was on energy 
conversion processes at the molecular level and in the third, on longrange electron and energy transfer in soluble polymers.

\section{MLCT EXCITED STATES}

In our work on synthesis an important advance was made in developing general procedures for the synthesis of side-chain derivatives of 2,2'-bipyridine. In this work we were able to develop general and versatile synthetic methods for the preparation of a variety of derivatized 2,2'-bipyridine compounds bearing a single functionalized side-chain at the 4-position. ${ }^{1}$ More recently the synthetic work was extended to the preparation of unsymmetrically substituted complexes of $\mathrm{Ru}(\mathrm{II})$. In this work a step-wise sequential procedure was developed for the incorporation of three different bipyridine ligands based on the polymeric precursor $\left[\mathrm{Ru}\left(\mathrm{CO}_{2}\right) \mathrm{Cl}_{2} \mathrm{l}_{n}\right.$. This is an important synthetic advance since it provides a general procedure for the preparation of sensitizers in complex molecular assemblies. 2

Our systematic studies on the characterization of MLCT excited states have been extended to the series $\mid \operatorname{Re}\left(4.4^{\prime}-(\mathrm{X})_{2}\right.$ bpy $)(\mathrm{CO})_{3}(4$ Lipy $)\left.\right|^{+}\left(\mathrm{X}=\mathrm{NH}_{2}, \mathrm{OCH}_{3}, \mathrm{CH}_{3}, \mathrm{CONE}_{2}, \mathrm{CO}_{2} \mathrm{Et} ; 4\right.$-Etpy is 4-ethylpyridine). By a combination of ground and excited state measurements and emission spectral fitting, we were able to conclude that these excited states have shortented lifetimes compared to related complexes of Ru(II) and Os(II) having similar energy gaps because of a higher contribution to nonradiative decay from low frequency modes and the solvent as well as from a contribution from a high frequency $\mathrm{CO}$ stretching mode. ${ }^{3}$ The observation was also made of large solvatochromic shifts for the metal-to-ligand charge transfer absorption bands in these complexes and rationalized by applying dielectric continuum theory. 4 In a more recent application, in collahoration with the group of Brian Dyer at Los Alamos and Carlo Bignozzi at Ferrara, we were able to utilize transient infrared spectroscopy to demonstrate that energy transfer occurs across the cyanide bridge in $\mid\left.($ bpy $)(\mathrm{CO})_{3} \operatorname{Re}(\mathrm{NC}) \mathrm{Ru}(\mathrm{CN})(\mathrm{bpy})_{2}\right|^{+}$following $\mathrm{Re} \rightarrow$ bpy excitation. The utilization of this technique relied on comparisons in $\mathrm{CO}$ and $\mathrm{CN}$ stretching modes for the transient observed following laser flash photolysis with those obtained for related ground and excited states. 5

We were also able to extend our knowledge of photophysical properties of complexes of Rull by a series of studies involving a 
combination of lifetime and emission measurements. In an extension of an earlier study on polypyridyl complexes of Os(II), we were able to use the results of low temperature emission fitting to obtain the required parameters (energy gap, quantum spacing, electronvibrational coupling constants, solvent reorganizational energy) to calculate the vibrational overlap factors for nonradiative decay. We were able to use these factors to calculate relative rate constants for nonradiative decay. ${ }^{6}$ In a second study, by acquiring temperature dependent lifetime data on a series of polypyridyl complexes of Os(II), we were able to demonstrate the contribution of a fourth MLCT state to excited state decay. Based on the results of this analysis, it is now possible to account for the nonradiative decay characteristics of this family of complexes over an extended temperature range. 7

The excited state studies were extended to complexes of Rull and $\mathrm{Os}^{\mathrm{Il}}$ containing a hydride ligand, e.g., cis- $\left|\mathrm{M}(\mathrm{bpy})_{2}(\mathrm{CO}) \mathrm{H}\right|+(\mathrm{M}=$ $\mathrm{Ru}, \mathrm{Os})$. The initial intent of the study was to explore the possibility of MLCT excitation and activation of the metal hydride bond. In fact, these molecules are stable photochemically. We did discover, however, that for $\mathrm{M}=\mathrm{Ru}$ there was a significant participation by $v(\mathrm{Ru}-\mathrm{H})$ in non radiative decay. ${ }^{8}$

\section{PHOTOINDUCED ELECTRON AND ENERGY TRANSFER ON SOLUBLE POLYMERS}

Our work on soluble polymers has been based on chemical derivatization of a 1:1 copolymerof styrene and 4chloromethylstyrene. In earlier work we had developed synthetic techniques for chemical modification based on nucleophilic displacement of chloride. The synthetic chemistry is sufficiently flexible that it allows for polymers of mixed content to be prepared where first one component is added with an additional component or components added in subsequent steps. In one series of experiments, the synthetic chemistry was exploited to demonstrate the existence of intermolecular energy and electron transfer shuttling between polymers of different compositions. In these experiments it was demonstrated that excitation of $\left|R u(b p y)_{3}\right|^{2+}$ in the presence of separate polymeric strands, one containing an anthracene derivative and a phenothiazine derivative and the second a derivative of paraquot led to a series of diffusional events. Energy transfer quenching by anthracene was followed by electron transfer from phenothiazine to the anthracene triplet to paraquat followed by 
intrastrand electron transfer from the anthracene cation. This experiment was designed to demonstrated new approach to energy conversion based on interstrand dynamics. ${ }^{9}$

In more recent work our attention was turned to intrastrand electron and energy transfer dynamics. One series of experiments was based on polymeric samples in which, of the average 30 available chloromethystyrene sites, 25 were occupied by a $\left[\mathrm{Ru}(\mathrm{bpy})_{3}\right]^{2+}$ derivative and 5 by a corresponding osmium derivative. Following $\mathrm{Ru}$ II $\rightarrow$ bpy excitation of this sample, rapid energy transfer occurred but only from $\mathrm{Ru}^{\mathrm{II}}{ }^{*}$ excited states that were formed next to Osil. Energy transfer from $\mathrm{Ru}^{\mathrm{II}}$ to $\mathrm{Os}^{\mathrm{II}}$ was favored by $0.4 \mathrm{eV}$. The same study demonstrated that energy transfer hopping from $\mathrm{Ru}^{\prime I^{*}}$ to $\mathrm{Ru}$ II along the polymeric backbone was relatively slow, $\mathrm{k}<1 \times 10^{6} \mathrm{~s}^{-}$ $1,10,11$

By using the same polymer it was also possible to explore intrastrand electron transfer. In these experiments initial $\mathrm{Ru}^{\mathrm{Il}} \rightarrow$ bpy excitation in the presence of the irreversible diazonium quencher $\mathrm{p}$ -

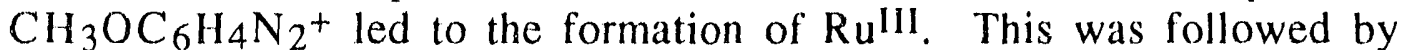
intra-strand oxidation of $\mathrm{Os}^{\mathrm{II}}$ by $\mathrm{Ru}^{\mathrm{III}}$, which is favored by $0.5 \mathrm{eV}$. As for energy transfer, electron transfer from $\mathrm{Ru}$ Ill to an adjacent Os ${ }^{11}$ was too rapid $\left(>2 \times 10^{8} \mathrm{~s}^{-1}\right)$ to be time-resolved experimentally using our current capabilities. However, it was possible to timeresolve intrastrand $\mathrm{Ru} \mathrm{u}^{\mathrm{II}} \rightarrow \mathrm{R} \mathrm{u}^{\mathrm{II}}$ electron transfer hopping by observing the bleach in a characteristic OsIl $\rightarrow$ bpy MLCT and following laser excitation. From these experiments a rate constant for $\mathrm{Ru}^{\text {II }} \rightarrow$ Rulll, self-exchange electron transfer of $5 \times 10^{6} \mathrm{~s}^{-1}$ was established. 10,11

In another series of experiments, based on fully loaded polymers containing, on the average, thirty $|R u(b p y) 3|^{2+}$ or $|\mathrm{Os}(\mathrm{bpy}) 2|^{2+}$ derivatives, we were able to demonstrate that photoexcitation in the presence of $\mathrm{p}^{-} \mathrm{O}_{2} \mathrm{NC}_{6} \mathrm{H}_{6} \mathrm{~N}_{2}+$ led to the build-up and storage of multiple oxidative equivalents. The importance of these experiments was that they demonstrated the feasibility of utilizing polymers as sources of multiple redox equivalents perhaps to drive catalytic systems for energy conversion. 12

The experiments on the mixed ruthenium-osmium polymers demonstated that intrastrand energy transfer between metal complex sites in not necessarily facile. In order to find ways to 
achieve facile energy transfer, the photophysical properties of polymers lightly loaded in $\mathrm{Ru}^{\mathrm{II}}$ and $\mathrm{O}$ sII $^{\mathrm{II}}$ and highly loaded in an anthracene derivative were investigated. The triplet excited state energy of the anthracene derivative $(1.8 \mathrm{eV})$ was between the MLCT excited state energies for $\mathrm{Ru}^{\mathrm{II}}$ and $\mathrm{Os}^{\mathrm{II}}$. We are able to demonstrate that following laser flash excitation at $\mathrm{Ru}^{\mathrm{II}}$, energy transfer occurred from $\mathrm{Ru}^{\prime *}$ to anthracene. This was followed by encrgy transfer hopping amongst anthracenes with the final step being energy transfer from triplet anthracene to OsII to give the OsIl-based MLCT excited state. ${ }^{13}$

\section{REVIEWS}

The DOE funded portion of our work on photochemistry provided the basis for three articles which summarized the current status of energy conversion based on MLCT excited states in molecular assemblies. One dealt with the theme of the photochemical reduction of $\mathrm{CO}_{2}$ and was presented at a Nobel Symposium on " $\mathrm{CO}_{2}$-fixation and $\mathrm{CO}_{2}$-reduction in Biological and Model Systems" in Stockholm in December, 1991. The second dealt with long-range electron and energy trnsfer in molecular assemblies. 15 The third summarized our results to date on soluble polymers. 16

\section{REFERENCES}

1. Ciana, L. D.; Hamachi, I.; Meyer, T. J. J. Org. Chem. 1989, 54,1731.

2. Strouse, G. F.; Anderson, P. A.; Schoonover, J. R.; Meyer, T. J.; Keene, F. R., submitted.

3. Worl, L. A.; Duesing, R.; Chen, P.; Ciana, L. D.; Meyer, T. J. J. Chem. Soc. Dalton Trans. 1991, p. 849.

4. Sullivan, B. P. J. Phys. Chem. 1989, 93, 24.

5. Schoonover, J.; Dyer, B.; Bignozzi, C.; Meyer, T. J. submitted.

6. Bargawi, K. R.; Murtaza, Z.; Meyer, T. J. J. Phys. Chem. 1991, 95, 47.

7. Lumpkin, R. S.; Kober, E. M.; Worl, L. A.; Murtaza, Z.; Meyer, T. J. J. Phys. Chem. 1990, 29, 2285. 
8. Megehee, E. G.; Meyer, T. J. Inorg. Chem. 1989, $28,4084$.

9. Younathan, J. N.; Jones, Jr., W. E.; Meyer, T. J. J. Phys. Chem. $1991,95,488$.

10. Baxter, S. M.; Jones, Jr., W. E.; Danielson, E.; Worl, L.; Strouse, G. F.; Younathan, J.; Meyer, T. J. Coord. Chem. Rev. 1991, 111, 47.

11. Baxter, S. M.; Jones, Jr., W. E.; Meyer, T. J. in preparation.

12. Worl, L. A.; Strouse, G. F.; Ycunathan, J. N.; Baxter, S. M.; Meyer, T. J. J. Am. Chem. Soc. 1990, 112, 7571.

13. Strouse, G. F.; Worl, L. A.; Younathan, J. N.; Meyer, T. J. J. Am. Chem. Soc. 1989, 111, 9101.

14. Meyer, T. J. Nobel Symposium on " $\mathrm{CO}_{2}$-Fixation and $\mathrm{CO}_{2}-$ Reduction in Biological and Model Systems", in press.

15. Meyer, T. J. Pure \& Applied Chem. 1990, 94, 239.

16. Jones, Jr., W. E.; Baxter, S. M.; Mecklenburg, S. L.; Erickson, B. W.; Peek, B. M.; Meyer, T. J., in "Supramolecular Chemistry", in press. 


\section{PUBLICATION LIST}

Metal-to-Ligand Charge-Transfer (MLCT) Photochemistry. Experimental Evidence for the Participation of a Higher Lying MLCT State in Polypyridyl Complexes of Ruthenium(II) and Osmium(II), R. S. Lumpkin, E. M. Kober, L. A. Worl, Z. Murtaza, T. J. Meyer, J. Phys. Chem., 1990, 94, 239-243.

Effect on MLCT Excited States of Electronic Delocalization in the Acceptor Ligand, Stephen Boyde, Geoffrey F. Strouse, Wayne E. Jones, Jr., and Thomas J. Meyer, J. Am. Chem. Soc., 1990, 112, $7395-7396$

Production and Storage of Multiple, Photochemical Redox Equivalents on Soluble Polymers, Laura A. Worl, Geoffrey F. Strouse, Janet N. Younathan, Steven M. Baxter, and Thomas J. Meyer, J. Am. Chem. Soc., 1990, 112, 7571-7578.

Calculation of Relative Nonradiative Decay Rate Constants from Emission Spectral Profiles. Polypyridyl Complexes of Ru(II), Khaled R. Barqawi, Zakir Murtaza, and Thomas J. Meyer, J. Phys. Chem., 1991, 95, 47-50.

Energy - and Electron-Transfer Shuttling by a Soluble, Bifunctional Redox Polymer, Janet N. Younathan, Wayne E. Jones, Jr., and Thomas J. Meyer, J. Phys. Chem., 1991, 95, 488-492.

Photophysical Properties of Polypyridyl Carbonyl Complexes of Rhenium(I), Laura A. Worl, Rich Duesing, Pingyun Chen, Leopoldo Della Ciana, and Thomas J. Meyer, J. Chem. Soc. Dalton Trans., $1991,849-858$.

Photoinduced Electron and Energy Transfer in Soluble Polymers. S.M. Baxter, W.E. Jones, Jr., E. Danielson, L. Worl, G. Strouse, J. Younathan, and T.J. Meyer, Coord. Chem. Rev., 1991, 111, 47-71.

\section{SUBMITTED OR IN PRESS}

Synthesis of Polypyridyl Complexes of Ruthenium(II) Containing Three different Bidentate Ligands. Geoffrey F. Strouse, Peter A. Anderson, Thomas J. Meyer, and F. Richard Keene. Submitted. 
The MLCT-dd Energy Gap in Pyridyl-Pyrimidine and Bis-Pyridine Complexes of Ruthenium(II). D. Paul Rillema, Charles B. Blanton, Randy J. Shaver, Donald C. Jackman, Massoud Boldaji, Stephanie Bundy, Laura A. Worl, and Thomas J. Meyer. Inorg. Chem., in press.

Long-Range Electron and Energy Transfer in Molecular Assemblies. Wayne E. Jones, Jr., Steven M. Baxter, Sandra L. Mecklenburg, Bruce. W. Erickson, Brian M. Peek, and Thomas J. Meyer. In NATO ASI Series, Kluwer, in press.

Photochemical Electron Transfer Applied to the Reduction of CO2. Thomas J. Meyer. 1991 Nobel Symposia " $\mathrm{CO}_{2}$-fixation and $\mathrm{CO}_{2}$ reduction in Biological and Model Systems." In press. 
